\title{
Longitudinal decrements in iron status during military training in female soldiers
}

\author{
James P. McClung ${ }^{1}$, J. Philip Karl ${ }^{1}$, Sonya J. Cable ${ }^{2}$, Kelly W. Williams ${ }^{2}$, Andrew J. Young ${ }^{1}$ \\ and Harris R. Lieberman ${ }^{1}$ \\ ${ }^{1}$ Military Nutrition Division, US Army Research Institute of Environmental Medicine (USARIEM), Natick, MA 01760, USA \\ ${ }^{2}$ Experimentation and Analysis Element, Directorate of Basic Combat Training, Fort Jackson, SC 29207, USA
}

(Received 4 November 2008 - Revised 4 December 2008 - Accepted 10 December 2008 - First published online 28 January 2009)

$\mathrm{Fe}$ is an essential micronutrient required for optimal cognitive and physical performance. Cross-sectional studies indicate that training degrades Fe status in female military personnel; however, longitudinal studies to measure the direct impact of military training on Fe status and performance have not been conducted. As such, the objective of the present study was to determine the longitudinal effects of military training on Fe status in female soldiers. Fe status was assessed in ninety-four female soldiers immediately before and following a 9-week basic combat training (BCT) course. Fe status indicators included $\mathrm{Hb}$, erythrocyte distribution width (RDW), serum ferritin, transferrin saturation and soluble transferrin receptor (sTfR). A 2-mile $(3 \cdot 2 \mathrm{~km})$ run test was performed at the end of BCT to assess aerobic performance. Fe status was affected by BCT, as all Fe status indicators, excluding $\mathrm{Hb}$, were diminished $(P \leq 0.01)$ at the end of BCT. Fe status indicators at the end of BCT (Hb and RDW) were associated $(P \leq 0.05)$ with running performance, as was the change in sTfR over the training period $(r 0.320 ; P \leq 0 \cdot 05)$. In conclusion, Fe status in female soldiers is degraded during BCT, and degraded Fe status is associated with diminished aerobic performance. Female athletes and military personnel should strive to maintain Fe status to optimise physical performance.

Iron: Iron deficiency: Hepcidin: Training: Soldiers

$\mathrm{Fe}$ is a nutritionally essential trace element that functions through incorporation into proteins and enzymes, including $\mathrm{Hb}$, myoglobin, cytochrome $\mathrm{c}$ and aconitase $^{(1)}$. The negative effects of Fe-deficiency anaemia on work capacity and physical performance have been well characterised in humans ${ }^{(2-4)}$ and are attributed to insufficient $\mathrm{O}_{2}$ transport by $\mathrm{Hb}$ to peripheral tissues ${ }^{(5)}$. The effects of moderate Fe deficiency without anaemia on performance are not as well described, although recent studies indicate that Fe supplementation may improve exercise endurance $^{(5)}$ and maintain ventilatory threshold in Fe-deficient non-anaemic athletes ${ }^{(6)}$. Furthermore, Fe deficiency without anaemia results in impaired aerobic adaptation and endurance capacity in untrained women ${ }^{(7,8)}$.

Fe deficiency and Fe-deficiency anaemia affect billions of individuals worldwide ${ }^{(9,10)}$. In the developed world, the greatest prevalence of poor Fe status is observed in premenopausal women, mainly due to suboptimal $\mathrm{Fe}$ intake and the regular loss of Fe through the menstrual cycle ${ }^{(11)}$. Recent data from the USA and the UK suggest that Fe deficiency affects between 16 and $21 \%$ of premenopausal women ${ }^{(12,13)}$. Female soldiers represent a population that may be at risk for poor $\mathrm{Fe}$ status, as these soldiers are of premenopausal age, may not consume adequate $\mathrm{Fe}^{(14)}$ and often enter military service with low Fe stores ${ }^{(15)}$. Poor Fe status could adversely affect female soldiers, as maintaining optimal physical performance is critical for operational deployment and the completion of required training courses, including basic combat training (BCT).

A number of studies indicate that physical activity has a negative effect on Fe status in women ${ }^{(16,17)}$. Furthermore, cross-sectional studies indicate that military training results in an increased prevalence of Fe deficiency and Fe-deficiency anaemia in female soldiers ${ }^{(18)}$. As such, the primary objective of the present longitudinal study was to confirm findings from previous cross-sectional studies indicating an effect of military training on Fe status. A secondary objective was to determine whether changes in $\mathrm{Fe}$ status indicators during training were predictive of physical performance at the end of the training period.

\section{Experimental methods}

\section{Volunteers and experimental design}

The present study was approved by the Human Use Review Committee at the US Army Research Institute of Environmental Medicine. Human subjects participated in these studies after giving their free and informed voluntary consent.

Abbreviations: BCT, basic combat training; RDW, erythrocyte distribution width; sTfR, soluble transferrin receptor; TS, transferrin saturation.

* Corresponding author: Dr James P. McClung, fax +1 508233 4869, email James.McClung@amedd.army.mil 
Investigators adhered to Army Regulation 70-25 and US Army Medical Research and Materiel Command Regulation 70-25 on the use of volunteers in research.

A total of ninety-four female soldiers completed this longitudinal study. The first timepoint was within 1 week of arrival at BCT (pre); the second timepoint was within 1 week of completion of BCT (post). All volunteers were not pregnant and had not exercised in the $8 \mathrm{~h}$ before fasted blood collection. Height and body weight were assessed at both timepoints. BCT consists of 9 weeks' military training, including both aerobic and muscle strength training ${ }^{(19)}$. Formalised daily physical training sessions occurred $4-6 \mathrm{~d} /$ week, and included $1-1.5 \mathrm{~h}$ cardiorespiratory and muscle strength training ${ }^{(20)}$. Cardiorespiratory training included activities such as road marching, distance running and sprinting. Muscle strength training included callisthenic exercises, sit-ups and push-ups. In addition to formalised physical training, military training included rappelling, bayonet training, live fire exercises, obstacle courses and prolonged standing in formation ${ }^{(18)}$. Recent studies using pedometers to assess ambulatory activity during BCT indicate that trainees perform an average of over $16000 \mathrm{steps} / \mathrm{d}$, the equivalent of nearly $12 \mathrm{~km}^{(20)}$. In comparison, data from civilian studies estimate average ambulatory activity to be between 6000 and $8000 \mathrm{steps} / \mathrm{d}^{(20,21)}$.

Upon entry to BCT, 1-mile $(1.6 \mathrm{~km})$ run time was collected as an indicator of initial fitness level. The mean 1-mile run time of this population was 9.9 (SD 1.1) min ( $n$ 71), which may be converted to a mean $\mathrm{VO}_{2}$ peak of 39.4 (SD 3.4) $\mathrm{ml} / \mathrm{kg}$ per min using a published equation for the estimation of $\mathrm{VO}_{2}$ peak from running time ${ }^{(22)}$. Hence, the average aerobic fitness levels of the volunteers that participated in the present study corresponds to approximately the 60th percentile for women aged $20-29$ years $^{(23)}$. Other demographic characteristics of the volunteers appear in Table 1.

\section{Sample collection and analysis}

Blood was collected by antecubital venepuncture into tubes (Vacutainer; Becton-Dickinson, Franklin Lakes, NJ, USA)

Table 1. Volunteer demographics

(Mean values and standard deviations for ninety-four subjects)

\begin{tabular}{|c|c|c|}
\hline & Mean & SD \\
\hline Age (years) & $20 \cdot 6$ & 3.9 \\
\hline Height $(\mathrm{cm})$ & $162 \cdot 4$ & $6 \cdot 3$ \\
\hline Weight, pre $(\mathrm{kg}) \dagger$ & $63 \cdot 2$ & 9.8 \\
\hline Weight, post $(\mathrm{kg}) \dagger$ & $63 \cdot 8^{*}$ & 8.6 \\
\hline \multicolumn{3}{|l|}{ Ethnicity $(n)$} \\
\hline Not Hispanic & & \\
\hline Hispanic & & \\
\hline \multicolumn{3}{|l|}{ Race $(n)$} \\
\hline White or Caucasian & & \\
\hline Black or African American & & \\
\hline Native American/Alaskan Native & & \\
\hline Asian & & \\
\hline Native Hawaiian/Pacific Islander & & \\
\hline
\end{tabular}

* Mean value was significantly different from that for 'Weight, pre' ( $P \leq 0.05$; paired $t$ test).

†'Pre' measures were collected during week 1 of basic combat training; 'post' measures were collected during the final week. containing the appropriate anticoagulant. Erythrocyte distribution width (RDW) and $\mathrm{Hb}$ were determined in whole blood on-site using a haematology analyser (Ac.T; Beckman Coulter, Fullerton, CA, USA; Sysmex XE-2100; Kobe, Japan). Serum samples were processed on-site, sampled, frozen and shipped to the Pennington Biomedical Research Center (Baton Rouge, LA, USA) for $\mathrm{Fe}$ status indicator assays. Total Fe-binding capacity and serum Fe were determined using a Beckman Coulter Synchron CX7 (Beckman Coulter). Serum ferritin was determined by microparticle enzyme immunoassay (IMx; Abbott Laboratories, Abbott Park, IL, USA). Transferrin saturation (TS) was determined by dividing serum $\mathrm{Fe}$ by total Fe-binding capacity ${ }^{(24)}$. Soluble transferrin receptor (sTfR) was determined in serum using an immunoassay according to the manufacturer's instructions (Quantikine IVD; R\&D Systems, Inc., Minneapolis, MN, USA). In the case of this immunoassay for sTfR, Fe deficiency is indicated where values exceed $28 \cdot 1 \mathrm{nmol} / \mathrm{l}$.

\section{Statistical analysis}

Statistical analysis was performed using commercially available statistical software (SPSS 15.0; SPSS, Inc., Chicago, IL, USA). Descriptive statistics are presented as mean values and standard deviations. Before means comparisons, normal distribution of variables was determined using the Kolmogorov-Smirnov test. For longitudinal comparisons of Fe status indicators, normally distributed means were compared using paired $t$ tests. For Fe status indicators that were not normally distributed, medians were compared using the Wilcoxon signed ranks test. Correlations between Fe status indicators and 2 -mile $(3.2 \mathrm{~km})$ run time were evaluated using Pearson's correlation and Spearman's rank correlation analyses as appropriate. Partial correlations between longitudinal changes in each Fe status indicator and 2 -mile $(3 \cdot 2 \mathrm{~km})$ run time were conducted while controlling for the pre-BCT concentration of each Fe status indicator. For all statistical analyses a maximum $P$ value of 0.05 was the necessary condition for statistical significance.

\section{Results}

Longitudinal changes in iron status following basic combat training

Nearly all Fe status indicators suggest a decline in Fe status at the end of the training period (Table 2). Markers of Fe transport and storage were diminished, as TS and serum ferritin were reduced $(P \leq 0.01)$ post-BCT. Mean TS was $42.7 \%$ lower at the end of BCT; median serum ferritin values decreased by $20 \cdot 1 \%$. Further, median RDW and sTfR were increased $(P \leq 0.01)$ at the end of BCT, also indicating reduced Fe status. Post-BCT RDW median levels were $107 \cdot 1 \%$ of the pre-BCT levels, whereas post-BCT sTfR median levels were $131.3 \%$ of the starting levels. Seven individuals would have been considered Fe deficient at the start of BCT using the sTfR cut-off value of $28.1 \mathrm{nmol} / \mathrm{l}$, whereas seventeen individuals would have been considered Fe deficient post-BCT. Hb values were significantly $(P \leq 0 \cdot 01)$ higher post-BCT compared with pre-BCT. 
Table 2. Longitudinal changes in iron status during military training

(Mean values and standard deviations or medians and ranges)

\begin{tabular}{|c|c|c|c|c|c|}
\hline & \multicolumn{2}{|c|}{ Pre $^{*}$} & \multicolumn{2}{|c|}{ Post* } & \multirow[b]{2}{*}{$P$} \\
\hline & Median & Range & Median & Range & \\
\hline \multicolumn{6}{|l|}{ Indicatort } \\
\hline $\mathrm{Hb}(\mathrm{g} / \mathrm{l})$ & & & & & $\leq 0.01$ \\
\hline Mean & \multicolumn{2}{|c|}{122} & \multicolumn{2}{|c|}{129} & \\
\hline SD & \multirow{2}{*}{\multicolumn{2}{|c|}{10}} & \multicolumn{2}{|c|}{11} & \\
\hline TS (\%) & & & & & $\leq 0.01$ \\
\hline Mean & \multicolumn{2}{|c|}{$26 \cdot 0$} & \multicolumn{2}{|c|}{14.9} & \\
\hline SD & \multicolumn{2}{|c|}{$13 \cdot 3$} & \multicolumn{2}{|c|}{$7 \cdot 7$} & \\
\hline \multicolumn{6}{|l|}{ Indicatorł } \\
\hline Ferritin (ng/ml) & $26 \cdot 9$ & $2 \cdot 2-152 \cdot 0$ & 21.5 & $2 \cdot 5-172 \cdot 0$ & $\leq 0.01$ \\
\hline RDW (\%) & $12 \cdot 6$ & $11 \cdot 3-16 \cdot 2$ & 13.5 & $11.9-18.5$ & $\leq 0.01$ \\
\hline sTfR (nmol/l) & $16 \cdot 0$ & $5 \cdot 0-58 \cdot 0$ & $21 \cdot 0$ & $9 \cdot 0-62 \cdot 0$ & $\leq 0.01$ \\
\hline
\end{tabular}

TS, transferrin saturation; RDW, erythrocyte distribution width; sTfR, soluble transferrin receptor.

* 'Pre' measures were collected during week 1 of basic combat training; 'post' measures were collected during the final week.

$\dagger P$ values were determined using paired $t$ tests $(n 94)$.

$\ddagger P$ values were determined using the Wilcoxon signed ranks test $(n 93-94)$.

\section{Correlations between iron status indicators and physical performance}

Correlation analyses between $\mathrm{Fe}$ status indicators and 2-mile $(3 \cdot 2 \mathrm{~km})$ running performance at the end of BCT were performed (Table 3). TS, RDW and $\mathrm{Hb}$ at the start of $\mathrm{BCT}$ were associated $(P \leq 0.05)$ with 2 -mile $(3.2 \mathrm{~km})$ running performance at the end of BCT. Furthermore, both $\mathrm{Hb}$ and RDW at the end of BCT were associated $(P \leq 0.05)$ with running time. When longitudinal change scores were calculated and utilised in correlation analyses, only the change in sTfR was associated $(P \leq 0.05)$ with running performance. The $r$ value was positive, indicating that the longitudinal decrement in Fe status reflected by increased sTfR was associated with diminished running performance at the end of BCT.

\section{Discussion}

Inadequate $\mathrm{Fe}$ intake ${ }^{(14)}$ and diminished $\mathrm{Fe}$ status ${ }^{(15)}$ have been reported previously in female military personnel. Furthermore, cross-sectional studies indicate that $\mathrm{Fe}$ status

Table 3. Correlations between iron status indicators and running performance during military trainingt

\begin{tabular}{lccc}
\hline Indicator & Pre‡ & Post & Change \\
\hline Ferritin & -0.091 & -0.010 & 0.002 \\
TS & $-0.416^{*}$ & -0.214 & -0.120 \\
RDW & $0.380^{*}$ & $0.427^{\star}$ & 0.140 \\
STfR & 0.120 & 0.237 & $0.320^{*}$ \\
Hb & $-0.404^{*}$ & $-0.452^{*}$ & -0.234 \\
\hline
\end{tabular}

TS, transferrin saturation; RDW, erythrocyte distribution width; sTfR, soluble transferrin receptor.

* Significant $(P \leq 0.05)$ correlation between Fe status indicators and 2-mile $(3.2 \mathrm{~km})$ run times.

†Pearson's correlation and Spearman's rank correlation coefficients ( $r$ values) were determined using $\mathrm{Fe}$ status indicator values and time to completion of a 2-mile $(3.2 \mathrm{~km})$ run at the end of basic combat training $(n 59)$.

‡'Pre' samples were collected during week 1 of basic combat training; 'post' measures were collected during the final week. 'Change' values represent correlation between 2-mile $(3.2 \mathrm{~km})$ run times and the difference between pre- and post-values. declines in female soldiers during $\mathrm{BCT}^{(18)}$. As such, the primary objective of the present study was to determine the longitudinal effect of $\mathrm{BCT}$ on $\mathrm{Fe}$ status. Our major finding was that all markers of $\mathrm{Fe}$ nutriture, with the exception of $\mathrm{Hb}$, indicate diminished $\mathrm{Fe}$ status following the training period. Diminished Fe status may have negative consequences for female soldiers, as the period following BCT includes advanced individualised training and possibly operational deployment; activities which require optimal immune, cognitive and physical capabilities.

Diminished $\mathrm{Fe}$ status has been observed in a number of populations following physical training. Early studies documented diminished $\mathrm{Hb}$ in athletes following periods of intense training ${ }^{(25,26)}$. The diminished $\mathrm{Hb}$ observed in these populations was often described as 'sports anaemia' and was attributed to the plasma volume expansion that occurs with physical training. More recently, the effect of physical training on $\mathrm{Fe}$ status has been demonstrated using multivariable models of $\mathrm{Fe}$ status ${ }^{(18)}$ and newly developed indicators of $\mathrm{Fe}$ status, suggesting that physical training may result in true degradations in overall $\mathrm{Fe}$ status, as opposed to an acute decrement in $\mathrm{Hb}$. For example, Di Santolo et al. ${ }^{(27)}$ recently reported that athletes who performed regular physical exercise (about $11 \mathrm{~h} /$ week) had diminished serum Fe and TS as well as increased sTfR as compared with sedentary controls. Furthermore, reduced serum ferritin levels ${ }^{(17)}$ and diminished serum $\mathrm{Fe}^{(28)}$ have been reported in female athletes during physical training. In the present study, we found that Fe status was reduced in female soldiers following a standardised military training regimen as demonstrated using a series of Fe status indicators, including serum ferritin, TS and sTfR. One weakness of the present study was the inability to control for potential changes in plasma volume that may have been experienced during military training. However, the use of multiple Fe status indictors diminishes the potential confounding effect of changes in plasma volume, as these indicators provide a dynamic response to diminished $\mathrm{Fe}$ status. For example, serum ferritin was reduced following BCT, which could indicate diminished Fe status, or dilution due to increased plasma volume. However, sTfR was elevated, demonstrating that $\mathrm{Fe}$ status was 
truly diminished, as sTfR may not have been significantly elevated had plasma volume been confounding our data.

The reduced levels of early Fe status indicators observed in female soldiers following BCT in the present longitudinal study confirm previous cross-sectional studies. However, the earlier cross-sectional studies found that the prevalence of anaemia was increased following military training ${ }^{(18)}$, whereas our data indicate that despite decreases in all other Fe status indicators, $\mathrm{Hb}$ was marginally elevated $(<10 \%)$ following training. This effect of BCT on $\mathrm{Hb}$ levels may indicate that the degree of Fe deficiency following BCT observed in the present study is less than reported in earlier studies, as Fe deficiency is known to occur in stages ${ }^{(1)}$. Alternatively, increased $\mathrm{Hb}$ levels coupled with diminished serum ferritin levels could indicate a shift in $\mathrm{Fe}$ metabolism away from storage proteins to proteins that function in $\mathrm{O}_{2}$ delivery. Elevated $\mathrm{Hb}$ levels coupled with diminished serum ferritin levels following exercise have been observed in previous studies. Blum et al. ${ }^{(29)}$ describe elevated $\mathrm{Hb}$ levels in premenopausal women following 6 weeks' participation in an aerobic exercise programme. This increase in $\mathrm{Hb}$ was coupled with reduced serum ferritin. Interestingly, $\mathrm{Hb}$ levels returned to baseline levels following 13 weeks' participation in the exercise programme, whereas serum ferritin levels remained diminished. The authors concluded that the stress of exercise may have stimulated an increase in the production of erythrocytes, resulting in increased $\mathrm{Hb}$, which caused an increased mobilisation of Fe from ferritin. A second potential explanation for the increased $\mathrm{Hb}$ levels observed in the present study could be reduced plasma volume due to dehydration. However, reduced plasma volume would have resulted in not only elevation in $\mathrm{Hb}$ levels, but other Fe status indicators as well. Regardless, our data indicate that early indicators of Fe storage and transport were negatively affected by BCT, even if $\mathrm{Hb}$ was increased.

Although the definitive mechanism explaining diminished Fe status following periods of physical training remains to be elucidated, a number of hypotheses have been proposed. Classical hypotheses include diminished dietary $\mathrm{Fe}$ intake $^{(14)}$, gastrointestinal bleeding ${ }^{(30)}, \mathrm{Fe}$ loss through sweat $^{(31)}$, increased whole-body Fe turnover ${ }^{(32)}$ and haematuria due to erythrocyte rupture in the foot during running ${ }^{(33)}$. Dietary $\mathrm{Fe}$ intake was not assessed in the present study, although recent studies with female recruits in the Israeli Defence Forces report average Fe intakes of approximately $15 \mathrm{mg} / \mathrm{d}$, which would account for $83 \%$ of the current RDA $(18 \mathrm{mg} / \mathrm{d})$ for $\mathrm{Fe}$ in the corresponding demographic group $^{(34)}$. In that study, mean dietary Fe intake was not different between volunteers with normal Fe status as compared with those with $\mathrm{Fe}$ deficiency or Fe-deficiency anaemia, suggesting that the development of poor Fe status in female soldiers may involve a multifaceted mechanism. Studies with athletic populations suggest that diminished Fe status may occur as a result of the production of pro-inflammatory cytokines, such as IL-6, in response to acute bouts of exercise, which may subsequently result in the release of hepcidin ${ }^{(35,36)}$. Hepcidin, a recently discovered protein that is synthesised and exported by the liver, confers a major role in $\mathrm{Fe}$ homeostasis, as it affects both Fe absorption at the enterocyte and cellular Fe export through the binding and degradation of ferropor$\operatorname{tin}^{(35)}$. This hypothesis is supported by the findings of Roecker et al. ${ }^{(37)}$, who reported increased urinary hepcidin excretion in female athletes following a marathon. Future studies should attempt to determine whether military training results in proinflammatory cytokine and subsequent hepcidin release.

Indicators of $\mathrm{Fe}$ status in the volunteers that participated in the present study were associated with physical performance. Levels of $\mathrm{Hb}$ and RDW were correlated with 2-mile $(3.2 \mathrm{~km})$ run times at the end of the study. The correlation between $\mathrm{Hb}$ levels and running performance was not unexpected, as the negative effects of reduced $\mathrm{O}_{2}$ delivery to tissue on physical performance have been well described ${ }^{(38)}$. However, our finding that the change in sTfR over the course of the training period was correlated with 2-mile $(3.2 \mathrm{~km})$ run time is novel and indicates that the decrement in Fe status observed in female soldiers had an effect on the ability of these soldiers to perform aerobically demanding tasks. Others have demonstrated the important relationship between sTfR and physical performance. Brownlie et al. ${ }^{(7,8)}$ reported improved work rate, maximal $\mathrm{O}_{2}$ uptake and performance on time trials using a cycle ergometer following Fe supplementation in individuals with elevated sTfR levels as compared with individuals with normal levels. Similar to our findings, changes in sTfR levels through these studies were correlated with improvements in performance at the end of the training period, indicating that sTfR may be an accurate measure of $\mathrm{Fe}$ status that is predictive of physical performance during training periods. It should be noted, however, that most studies indicate that the relationship between sTfR and performance is typically strongest in individuals with levels of sTfR that approach Fe deficiency. In the present study, sTfR-derived cut-off values for Fe deficiency indicate that seven volunteers were Fe deficient pre-BCT; seventeen volunteers were Fe deficient post-BCT.

In summary, the major finding of the present longitudinal study was that indicators of Fe status were diminished following BCT in female soldiers. Fe status indicators were predictive of physical performance, and the decrement in sTfR observed during the training period correlated with 2 -mile $(3.2 \mathrm{~km})$ run time. These findings indicate that Fe status is affected by training in female soldiers and that degraded Fe status during training affects aerobic performance. Future studies should aim to determine the cause of degraded Fe status during training periods in athletes and soldiers, to include the relative contribution of changes in plasma volume, dietary Fe intake and the effects of inflammation. Preventing the decrement in Fe status that occurs during training periods may be essential to optimise physical performance in female soldiers, athletes and workers regularly engaged in physically demanding tasks.

\section{Acknowledgements}

First and foremost, the authors wish to acknowledge the soldier volunteers that participated in the present study as well as the command staff at Fort Jackson, South Carolina for allowing access to soldiers. The authors also wish to acknowledge Dr Jennifer Rood and her staff at the Pennington Biomedical Research Center for their contributions to data collection and performance of $\mathrm{Fe}$ status indicator assays. Nancy Andersen, Louis Marchitelli, Nelson Morales-Martinez, Michael Stanger and Sgt Tyson Tarr all made significant technical contributions to the experiments detailed in this paper. J. P. M. contributed to study design, data collection 
and manuscript preparation. J. P. K., S. J. C. and K. W. W. participated in data collection, statistical analysis and study management. H. R. L. and A. J. Y. contributed to study design and manuscript preparation. The present study was supported by the US Army Medical Research and Materiel Command.

The opinions or assertions contained herein are the private views of the authors and are not to be construed as official or as reflecting the views of the Army or the Department of Defense. Any citations of commercial organisations and trade names in this report do not constitute an official Department of the Army endorsement of approval of the products or services of these organisations.

Portions of this paper were presented in abstract form at Experimental Biology 2007, 28 April-2 May and NATO HFM-158, 13-15 October 2008.

The authors have no conflicts of interest to report.

\section{References}

1. Dallman PR (1986) Biochemical basis for the manifestations of iron deficiency. Annu Rev Nutr 6, 13-40.

2. Gardner G, Edgerton V, Senewiratne B, et al. (1977) Physical work capacity and metabolic stress in subjects with irondeficiency anaemia. Am J Clin Nutr 30, 910-917.

3. Tufts D, Haas JD, Beard JL, et al. (1985) Distribution of hemoglobin and functional consequences of anemia in adult males at high altitude. Am J Clin Nutr 42, 1-11.

4. Celsing F \& Ekblom B (1986) Anemia causes a relative decrease in blood lactate concentration during exercise. Eur $J$ Appl Physiol Occup Physiol 55, 74-78.

5. Hinton PS, Giordano C, Brownlie T, et al. (2000) Iron supplementation improves endurance after training in iron-depleted, nonanemic women. J Appl Physiol 88, 1103-1111.

6. Hinton PS \& Sinclair LM (2007) Iron supplementation maintains ventilatory threshold and improves energetic efficiency in iron-deficient nonanemic athletes. Eur J Clin Nutr 61, 30-39.

7. Brownlie T IV, Utermohlen V, Hinton PS, et al. (2002) Marginal iron deficiency without anemia impairs aerobic adaptation among previously untrained women. Am J Clin Nutr 75, 734-742.

8. Brownlie T IV, Utermohlen V, Hinton PS, et al. (2004) Tissue iron deficiency without anemia impairs adaptation in endurance capacity after aerobic training in previously untrained women. Am J Clin Nutr 79, 437-443.

9. DeMaeyer E \& Adiels-Tegman M (1985) The prevalence of anemia in the world. World Health Stat $Q$ 38, 302-316.

10. Stoltzfus R (2001) Defining iron-deficiency anemia in public health terms: time for reflection. J Nutr 131, 565S-567S.

11. Harvey LJ, Armah CN, Dainty JR, et al. (2005) Impact of menstrual blood loss and diet on iron deficiency among women in the UK. Br J Nutr 94, 557-564.

12. Looker AC, Cogswell ME \& Gunter MT (2002) Iron deficiency - United States, 1999-2000. MMWR Morb Mortal Wkly Rep 51, 897-899.

13. Heath AL \& Fairweather-Tait SJ (2002) Clinical implications of changes in the modern diet: iron intake, absorption, and status. Best Pract Res Clin Haematol 15, 225-241.

14. King N, Fridlund KE \& Askew EW (1993) Nutrition issues of military women. J Am Coll Nutr 12, 344-348.

15. Dubnov G, Foldes AJ, Mann G, et al. (2006) High prevalence of iron deficiency and anemia in female military recruits. Mil Med 171, 866-869.

16. Blum SM \& Sherman AR (1986) The effects of fitness-type exercise on iron status in adult women. Am J Clin Nutr 43, $456-463$.
17. Ashenden MJ, Martin DT, Dobson GP, et al. (1998) Serum ferritin and anemia in trained female athletes. Int J Sport Nutr $\mathbf{8}$, 223-229.

18. McClung JP, Marchitelli LJ, Friedl KE, et al. (2006) Prevalence of iron deficiency and iron deficiency anemia among three populations of female military personnel in the US Army. J Am Coll Nutr 25, 64-69.

19. Knapik JJ, Canham-Chervak M, Hauret K, et al. (2002) Seasonal variations in injury rates during US Army basic combat training. Ann Occup Hyg 46, 15-23.

20. Knapik JJ, Darakjy S, Hauret KG, et al. (2007) Ambulatory physical activity during United States Army basic combat training. Int J Sports Med 28, 106-115.

21. Tudor-Locke C, Ainsworth BE, Whitt MC, et al. (2001) The relationship between pedometer-determined ambulatory activity and body composition variables. Int $J$ Obes $\mathbf{2 5}$, 1571-1578.

22. Cureton KJ, Sloniger MA, O’Bannon JP, et al. (1995) A generalized equation for prediction of $\mathrm{VO}_{2}$ peak from 1-mile run/ walk performance. Med Sci Sports Exerc 27, 445-451.

23. American College of Sports Medicine (2006) Health-related physical fitness testing and interpretation. In ACSM's Guidelines for Exercise Testing and Prescription, 7th ed. pp. 79 [Whatley WH, editor]. Philadelphia, PA: Lippincott, Williams \& Wilkins.

24. Looker AC, Gunter EW \& Johnson CL (1995) Methods to assess iron status in various NHANES surveys. Nutr Rev 53, 246-254.

25. Yoshimura H (1970) Anemia during physical training (sports anemia). Nutr Rev 28, 251-253.

26. Radomski MW, Sabiston BH \& Isoard P (1980) Development of "sports anemia" in physically fit men after daily sustained submaximal exercise. Aviat Space Environ Med 51, 41-45.

27. Di Santolo M, Stel G, Banfi G, et al. (2008) Anemia and iron status in young fertile non-professional female athletes. Eur $J$ Appl Physiol 102, 703-709.

28. Magazanik A, Weinstein Y, Dlin RA, et al. (1988) Iron deficiency caused by 7 weeks of intensive physical exercise. Eur J Appl Physiol Occup Physiol 57, 198-202.

29. Blum SM, Sherman AR \& Boileau RA (1986) The effects of fitness-type exercise on iron status in adult women. Am J Clin Nutr 43, 456-463.

30. Stewart JG, Ahlquist DA, McGill DB, et al. (1984) Gastrointestinal blood loss and anemia in runners. Ann Intern Med 100, 843-845

31. Brune M, Magnusson B, Persson H, et al. (1986) Iron losses in sweat. Am J Clin Nutr 43, 438-443.

32. Ehn L, Carlmark B \& Hoglund S (1980) Iron status in athletes involved in intense physical activity. Med Sci Sports Exerc 12, $61-64$.

33. Siegel AJ, Hennekens CH, Solomon HS, et al. (1979) Exerciserelated hematuria: findings in a group of marathon runners. JAMA 241, 391-392.

34. Israeli E, Merkel D, Constantini N, et al. (2008) Iron deficiency and the role of nutrition among female military recruits. Med Sci Sports Exerc 40, S685-S690.

35. Ganz T \& Nemeth E (2006) Hepcidin and regulation of body iron metabolism. Am J Physiol Gastrointest Liver Physiol 290, G199-G203.

36. Peeling P, Dawson B, Goodman C, et al. (2008) Athletic induced iron deficiency: new insights into the role of inflammation, cytokines, and hormones. Eur J Appl Physiol 103, 381-391.

37. Roecker L, Meier-Buttermilch R, Brechtel L, et al. (2005) Ironregulatory protein hepcidin is increased in female athletes after a marathon. Eur J Appl Physiol 95, 569-571.

38. Beard J \& Tobin B (2000) Iron status and exercise. Am J Clin Nutr 72, 594S-597S. 